\title{
Influence of On-site Interpretation Intensity on Visitors to Natural Areas
}

\author{
Michael Hughes \\ Curtin Sustainable Tourism Centre, Curtin University of Technology, \\ GPO Box U1987, Perth, WA 6485, Australia
}

\section{Angus Morrison-Saunders \\ School of Environmental Science, Murdoch University, South Street, Murdoch, WA 6150, Australia}

There has been some debate about the benefits of high or low intensity use of on-site media at natural areas. The former may be viewed as overkill while the latter may not achieve the intended aims. Two similar natural area sites in Australia were selected with respective high and low intensity use of on-site interpretation. Visitors at each site were surveyed immediately before and after their experience to determine site influences on site perceptions and environmental attitudes. Comparative analysis revealed the intensity of interpretation did not appear to affect perceptions or attitude influence, while the character of the site experience and key visitor variables did. Site design needs to reflect interpretive media design to ensure visitor activities and subsequent effects on attitudes are consistent with conservation objectives.

Keywords: environmental attitude, environmental interpretation, natural area, site perceptions

\section{Introduction}

On-site environmental interpretation is a form of communication that encourages visitors to discover new ways of thinking about their natural surroundings. Interpretation is also used to assist in achievement of conservation objectives by natural area managers. To this end, interpretation is commonly used as an important part of natural area management, often incorporating a variety of methods (ANZECC, 1999; McArthur, 1994).

Interpretation at a site may be considered in terms of the quantity and type of media installed. Comparison of quantity and type of interpretation between sites may then be expressed in terms of intensity. As examples of the spectrum of intensity, interpersonal media (such as human guides) may be a more intense form of interpretation than text based media. A guide incorporates active delivery of messages with a multi-sensory, complex social interaction when communicating with visitors. This represents a pro-active form of communication that may act to draw visitors in and shape messages to suit personal contexts. On the other hand, text based media is a passive form of communication (with restricted sensory stimulation) where visitors must work to extract meaning from a written message. Alternatively, installing many signs or employing many guides at a site may be seen as a higher intensity of interpretation than few signs or guides. Thus it is assumed that interpretation intensity increases not just with the quantity 
used at a site (number of signs, guides and so on) but also with increased engagement of multiple senses and more active social interaction between visitors and site staff. Interpretation intensity has been a topic of debate in relation to how varying approaches influence visitors at a site as follows.

When considering appropriate intensity of on-site interpretation, Roggenbuck (1992) warned that a cautious approach is preferable in order to avoid overwhelming the visitor. The intent to positively influence the visitor using intensive on-site interpretation may backfire by ruining the visitors' sense of exploration and discovery. This in turn may generate negative visitor impressions of the site experience. In this vein, McKercher (1993) observed that visitors were generally not anthropologists or ecologists seeking intellectual enlightenment. Rather, they may be viewed as consumers of natural area experiences seeking enjoyable leisure encounters. Intensive use of on-site interpretation may result in information overload. This in turn may alter what was intended as a nature based leisure experience into what may seem to be a return to the classroom or a form of eco-preaching. As a result, visitors may ultimately boycott the destination given the negative experiences generated in this way. This would suggest that carefully regulating the intensity of on-site interpretation is required such that it does not overwhelm the visitor (Bramwell \& Lane, 1993).

Howard (1998) commented that some experiences may only require a low intensity, or even absence, of interpretation. He claimed that some experiences were implicitly significant to visitors. In support of this, Howard (1998) stated, 'the sunset at Uluru (central Australia) or swimming with Whale Sharks needs no explanation'. Field and Gough (1998) refer to this approach as, 'enrichment without words'. This rests on the idea that simply being in a natural setting can be meaningful and provoke visitors into viewing their surroundings in new ways. Provocation of thought is a central theme of interpretation in practice. If an environment or experience is intrinsically provocative, it seems logical that any on-site interpretation would be redundant.

On the other hand, low intensity approaches to on-site interpretation may result in the meaning or significance of an experience being lost to the visitor (Ballantyne, 1998). Minimalist interpretation relies on the visitor being able to 'see' the meaning or have a fulfilling experience of a site without facilitation. With low intensity interpretation, it is possible that visitors may not recognise the significance or meaning of an experience. Most experiences have multiple layers of meaning, some of which may not be immediately obvious to visitors without facilitation (Uzzell, 1998). For example, while the sunset at Uluru may be an amazing spectacle, interpretation may serve the purpose of facilitating understanding beyond the aesthetic beauty of the experience. To paraphrase Rolston (1998), a natural area cannot always be fully understood simply by looking long and hard at it. This may be especially so if visitors wish to focus on the minutiae of a natural area or when encountering unfamiliar or strange phenomena.

In summary, a site with a low intensity of interpretation relies more on the ability of the visitor to recognise its significance and derive meaning from the experience (Howard, 1998). If the visitor is not able to achieve this, the experience may have little impact or sense of fulfilment. Alternately, a high intensity interpretation site 
may facilitate the development of meaning but may also be overwhelming for the visitor and result in negative feelings about the site experience.

The purpose of this study was to investigate the influence of the intensity of interpretation on visitors' environmental attitude and perceptions of the site experience. Previously, we found that low intensity use of interpretive signs at a site in Western Australia created disquiet in surveyed visitors. They felt they were lacking in information while experiencing the trails at the site and wanted knowledge at hand regarding their forest surroundings. The low intensity of interpretation seemed to reduce the quality of the experience for visitors (Hughes \& Morrison-Saunders, 2002). This study investigated the influence of two similar sized sites in Western Australia managed by the same agency but with differing approaches to interpretation, on visitor attitudes and perceptions. The Treetop Walk (TTW) was designed with a minimalist approach to interpretation, to 'let the site speak for itself' (Field \& Gough, 1998). Penguin Island has a higher intensity of interpretation. Our examination of interpretation intensity included on-site media and the type and range of activities incorporated into the site design.

\section{Site Descriptions}

Both sites are situated in the southwest coastal region of Australia. Penguin Island is located in a marine park on the western coast approximately $40 \mathrm{~km}$ south of the state's capital, Perth (Figure 1). The island provides important

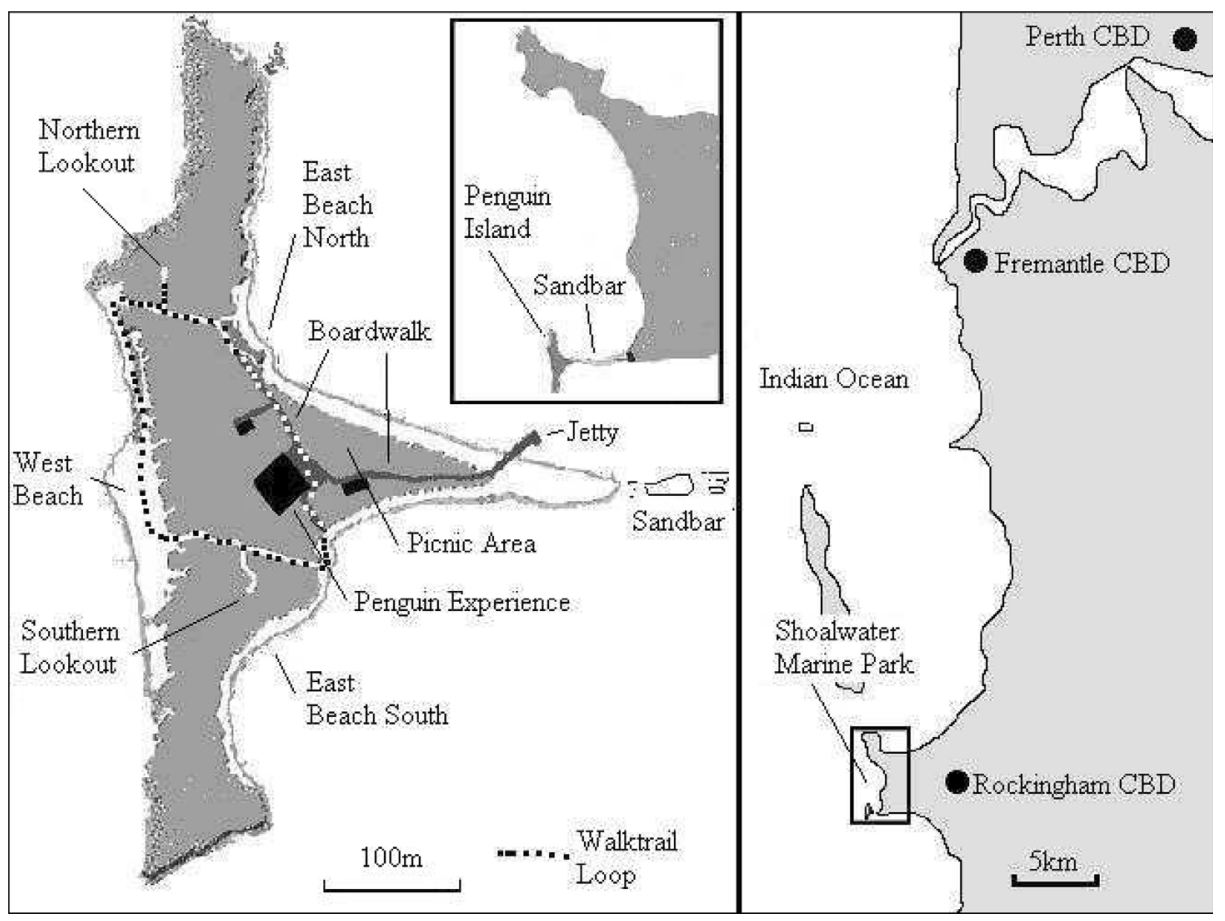

Figure 1 Location and layout of Penguin Island. 
breeding sites for the northern most population of Little Penguin (CALM, 1996). It is also has a long history of European recreational use dating back to the early 20th century and is currently used for a range of aquatic based activities (Dans, 1997). Penguin Island has a walk trail loop (combination of boardwalks, sand track and beach), visitor centre, picnic area and two swimming beaches. It caters for activities ranging from active recreational to educational pursuits. Access to the island is by a ferry service, personal water craft or a semi-submerged sandbar. Owing to the predictable and controlled character and associated fee, the survey focused on visitors using the ferry as access. Ferry ticket holders are given complimentary access to the Penguin Experience visitor centre and ranger talks at the centre are timed to largely coincide with ferry arrival times. Thus ferry users were more likely to experience the on-site interpretive media to a greater extent than other visitors. This ensured the Penguin Island sample was exposed to a higher intensity of interpretation than the TTW sample. Further justification of this approach may be found in Hughes and Morrison-Saunders (2005).

The TTW is located in a national park on the southern coast approximately $400 \mathrm{~km}$ south of Perth and $50 \mathrm{~km}$ west of the regional centre of Denmark (Figure 2). The site is located in a small area of forest dominated by giant Tingle trees that have been a tourism focus since the early 20th century. The current experience (constructed in 1996) consists of two $600 \mathrm{~m}$ walk trail loops through the forest - one at ground level (Ancient Empire Walk) and a free-standing catwalk rising to canopy height (Tree Top Walk). The TTW is the centrepiece of the site. It is constructed from a series of $60 \mathrm{~m}$ flexible metal bridge spans resting on large flexible metal pylons. At it highest point, visitors are $40 \mathrm{~m}$ above ground level. Visitors access the site from a car park via a single entry and exit pathway and ticket counter.

The sites were selected owing to some fundamental similarities in character while having distinct differences in on-site interpretation techniques. Both sites are managed by the Department of Conservation and Land Management (CALM) and are relatively small areas that have been established to protect ecologically unique phenomena. Both incorporate a controlled method of visitor access coupled with an entry fee and are centred on distinctive facilities used to view unique natural phenomena. Penguin Island has a small visitor centre (the Penguin Experience) based around a viewing facility housing rescued orphaned and injured Little Penguins. This affords an opportunity to see these birds that are otherwise unlikely to be seen by visitors at Penguin Island. The TTW was constructed in the sole remaining pocket of Tingle Forest left in the world. These Eucalypt trees have a notably broad girth (circumference up to $16 \mathrm{~m}$ ) and may grow up to $60 \mathrm{~m}$ tall. Many have hollow boles through which visitors may pass on ground level board walks or view from canopy level on the distinctive 'TTW'. Finally, both sites have interpretive media designed and installed by CALM. The interpretation is based on a strong conservation ethic stemming from CALM's role as a government conservation agency bounded by the Conservation and Land Management Act (1984, WA) and Wildlife Conservation Act (1950, WA).

The essential difference between the sites as tourist destinations (apart from obvious environmental/geographical aspects) relates to the intensity of 

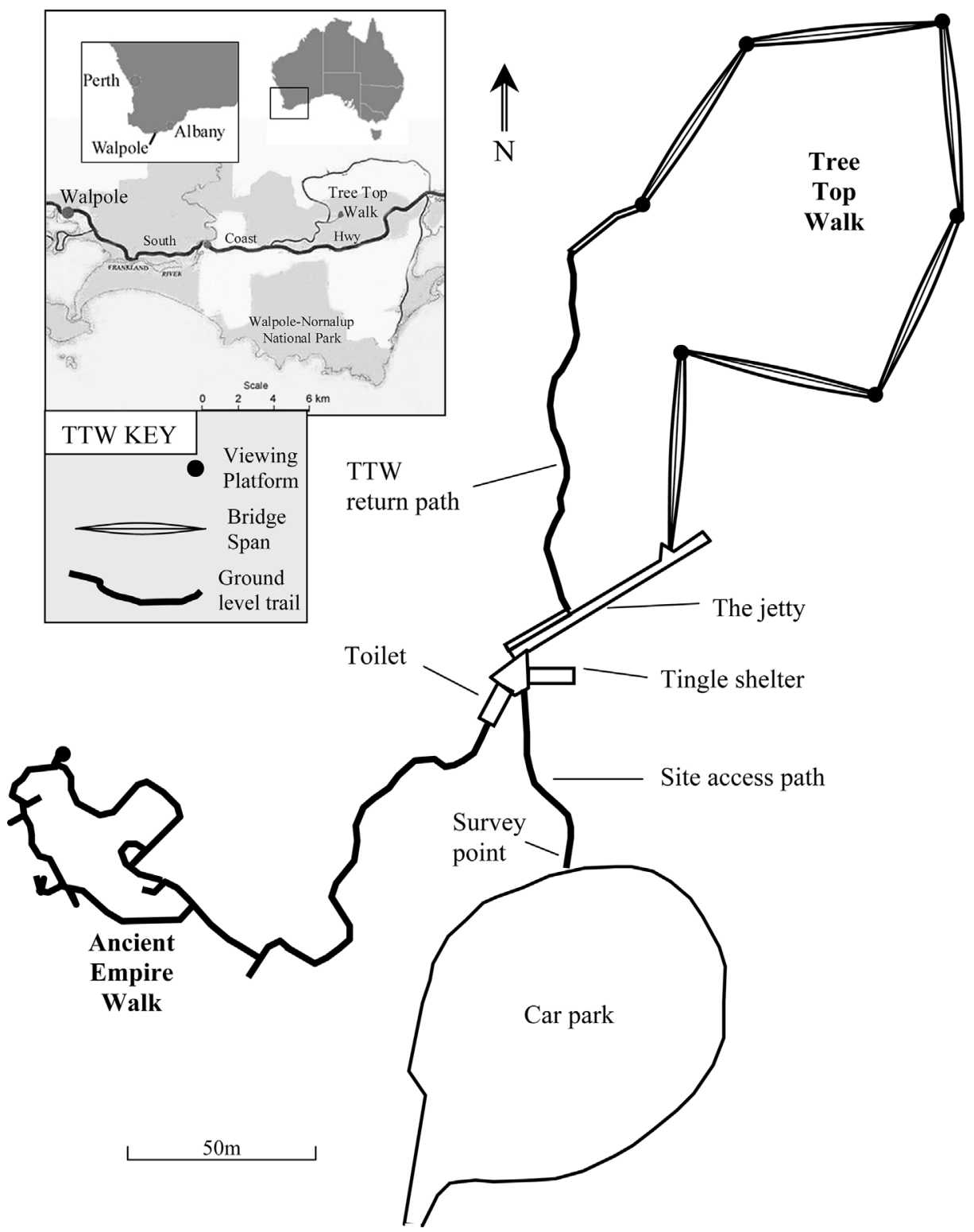

Figure 2 Location and layout of Tree Top Walk.

interpretation used and the range and type of visitor experiences offered. The TTW uses a low intensity of interpretation and activities while Penguin Island has a relatively higher intensity of these components (Table 1). These similarities and differences enabled comparisons to be made regarding the influence of the differing intensities of experience on visitor attitudes and perceptions. 
Table 1 Comparison of interpretation media and activities available at TTW and Penguin Island sites

\begin{tabular}{|c|c|c|}
\hline & TTW & Penguin Island \\
\hline On-site media & $\begin{array}{ll}\text { - } & \text { Signs. } \\
\text { - Sales information. } \\
\text { staff. }\end{array}$ & $\begin{array}{l}\text { - } \quad \text { Signs, pamphlets, brochures. } \\
\text { - Touch-tables with marine biological } \\
\text { artefacts. } \\
\text { - Ranger presentation. } \\
\text { - Information staff, ferry operator } \\
\text { introductory talk. }\end{array}$ \\
\hline Activities & $\begin{array}{l}\text { - } \text { Tree top and } \\
\text { ground level walk } \\
\text { trail loops. } \\
\text { - Souvenir shop. }\end{array}$ & $\begin{array}{l}\text { - Island walk trail loop with look outs. } \\
\text { - The Penguin Experience - penguin } \\
\text { viewing facility. } \\
\text { - } \text { Bird watching. } \\
\text { Picnicking, fishing, swimming, } \\
\text { (varing, snorkelling, surfing etc... } \\
\text { activities). }\end{array}$ \\
\hline
\end{tabular}

\section{Method}

We surveyed visitors at both sites immediately before and after their experience. The questionnaire was designed in consultation with a social scientist with experience in designing visitor surveys and CALM management staff along with the limited publications about visitor use of Penguin Island. There had been no previous visitor surveys conducted at the TTW. Pilot surveys were conducted at each site. The pilot was used to ensure the questionnaire was comprehensible to visitors and able to be completed within the restricted time frame of the Penguin Island ferry crossing.

Survey forms were personally distributed to visitors for completion on-site, immediately before and after their visit. A multiple choice survey design was adopted owing to the time restrictions imposed by the short ferry crossing at Penguin Island. For consistency, the same design was applied at each site. While multiple choice responses do not provide the same richness of data as other more narrative forms of questioning, they do provide a useful indication of visitor response to the issues raised (Neuman, 2000).

The questionnaire included two key elements, perceptions of site and environmental attitude measures, included in the before and after experience surveys. The questionnaire completed before the experience also requested information about the reason for visitation and whether or not the respondent was a repeat visitor to the island. The questionnaire completed after the experience requested information regarding interpretive media used, activities undertaken and demographic data such as sex, age, place of residence and who the respondent was visiting the island with.

Environmental attitudes were measured using a modified version of the New Environmental Paradigm scale devised by Dunlap and Van Liere (1978) and subsequently used by Jurowski et al. (1995) and Manning et al. (1999) among others. The modified version we used in this study used 10 statements that collectively contained the anthropocentric and ecocentric themes 
expressed in the original scale. However, the statements were worded in specific reference to each site. Five statements expressed attitudes supporting human use of the site as the dominant management priority; for example, 'Humans have a right to modify Penguin Island to suit their needs'. Five statements expressed attitudes supporting management for the intrinsic ecological value over human use; for example, 'Ideally, humans should not be allowed to visit this forest to ensure it is not damaged or degraded'. The statements were selected in consultation with a social scientist and based on issues identified by management staff and Western Australian tourism organisations. A five point Likert scale was used to ascertain the extent to which respondents agreed or disagreed with these statements.

Perceptions of the site experience were measured using statements adapted from Manning et al. (1999) and Rolston (1998) that reflect perceived benefits of natural area experiences. Statements referred specifically to the respective site experiences. For example, 'Opportunity to enjoy the beauty of the forest' and 'Opportunity to participate in recreation on Penguin Island'. A more detailed description may be found in Hughes and Morrison-Saunders (2003). Participants responded to the statements by indicating how applicable each experiential aspect was to their experience on a five point scale from not at all important to very important.

Surveys at Penguin Island were conducted on the ferry servicing the island during February, April, November and December 2001. The ferry service does not operate over the winter months (May to August) and the island is officially closed at night. To obtain an individually paired before and after sample, visitors were asked to write their ferry ticket number on the survey forms.

Surveys at the TTW were carried out in January, February and December of 2001, and then March 2002 (opening hours 9 am-5 pm). Visitors were surveyed immediately before entering and after exiting the TTW site via the single access path. A numbering system was used to enable individual pairing of responses. To test for reactivity bias owing to the completion of a paired, before and after survey, a group of visitors at each site were invited to complete a survey after experiencing the site only. The survey period includes samples from the beginning, middle and end of the peak visitation season.

All data was analysed at $\alpha=0.05$ using the SPSS statistical package.

\section{Findings}

A total of 107 visitors completed paired surveys at Penguin Island and 212 at the TTW site (35\% refusal rate at each site). The difference in the paired sample size is a reflection of restrictions on survey distribution imposed by the Penguin Island ferry crossing. TTW visitors were able to delay their entry and exit as required allowing flexibility in the timing of survey completion. Penguin Island visitors were required to adhere to the timing of the ferry crossing (about 7 minutes), exiting the craft on arrival to allow return passengers to board. This meant surveys had to be distributed after boarding but before the ferry embarked ( 5 to 10 minutes), limiting the number able to be completed on any one trip.

The vast majority of Penguin Island respondents (90\%) accessed some form of interpretation. Most respondents $(87 \%)$ visited the Penguin Experience, the 
principal source of interpretation on the island, including the venue for ranger presentations. About $60 \%$ of respondents used the touch tables and about $30 \%$ indicated they read interpretive signs. The primary source of interpretation available at the TTW site was text based signs, which $90 \%$ of respondents indicated they had used to some extent. Thus Penguin Island respondents were exposed to more intensive interpretation than those at the TTW. The sample size of respondents indicating they did not use any interpretive media at each site was too small for meaningful comparative analysis. This small sub-group was excluded from further analysis to ensure data integrity.

At each site, 50 visitors were exclusively surveyed after the experience for reactivity bias testing. Comparative analysis indicated no significant difference in response to attitudes or perceptions of the site experience between the paired and after experience only respondents. The remaining discussion relates to the paired survey samples only. Key findings relate to visitor demographics, site perceptions and attitudes to natural areas.

\section{Survey respondent demographics}

Basic demographic data (age groups, social groups and gender) was comparable for both TTW and Penguin Island and consistent with the broader natural area visitor population in Australia (Austats, 2003). However, natural area visitation frequency and repeat visitation data was markedly different between the two sites.

The Penguin Island sample had a much higher proportion of repeat visitor respondents $(47 \%)$ compared to the TTW sample $(13 \%)\left(\chi^{2}=50.95, d f=1\right.$, $p<0.001)$. The repeat visitors to each site had markedly different responses. Repeat visitors to the TTW site were primarily showing others the experience while Penguin Island repeat visitor respondents were primarily there to experience a specific aspect of the island again for themselves $\left(\chi^{2}=13.41, d f=1\right.$, $p<0.001)$.

These differences may be explained by the activities available at each site. Penguin Island enables a number of recreational pastimes (e.g. fishing, swimming, picnicking) and is close to urban areas. The TTW site is comparatively remote from major urban areas but is on a major tourism travel route. The TTW restricts visitors to a limited range of activities based on passive observation and exploration of the natural area. Fakeye and Crompton (1992) and Ballantyne et al. (1998) noted that repeat visitors were more interested in socialisation and active recreation in natural areas rather than exploration and education. Thus, it is logical that a site that does not cater specifically for socialisation or active recreational activities (TTW) will have a lower rate of repeat visitation than one that does (Penguin Island).

\section{Environmental attitude}

Before-visit survey data at both sites demonstrated an ecocentric attitude of respondents toward the environment as did the survey data collected after the experience. The pattern in response to the statements at the two sites suggested respondents were relatively more ecocentric in response to 'Human use' of natural areas than when responding to the 'Intrinsic ecological value' of natural areas. The disparity in response to the 'Human use' statements as 
compared with the 'Intrinsic ecological value' statements was markedly less after the site experiences than before the experiences at both sites. However, while the before and after environmental attitude data were similar for the respective sites, the magnitude and direction of change in response was quite distinct.

Examination of mean individual change in environmental attitude revealed that visitors responded significantly differently at the respective sites in relation to the 'Intrinsic ecological value' $(z=-2.97, p<0.01)$ and 'Human use' statements $(z=-2.60, p<0.01)$. The difference in the change in response to 'Total' environmental attitude (Figure 3) was also significant according to the MannWhitney Test $(z=2.40, p<0.02)$.

To explain this, we postulated that the difference may have been due to the much higher proportion of repeat visitors to Penguin Island as compared with the TTW. Repeat visitors may express different attitudes to first time visitors given the different context and purpose of their visit. However, no significant relationship was found between repeat visitation and environmental attitude.

The different environmental attitude response at the respective sites is of interest. Both the TTW site and Penguin Island promote a strong conservation message to visitors in terms of the physical design (e.g. controlled walkways to avoid trampling of sensitive areas) and on-site interpretation messages. Apparently in accordance with these messages, the measured change in environmental attitude response of the TTW sample indicated an increased ecocentric response across all three components ('Human use', 'Intrinsic ecological value', 'Total' attitude score). On the other hand, the Penguin Island respondents demonstrated a significant anthropocentric mean shift in response to the 'Human use' of natural areas. Comparison of environmental attitude

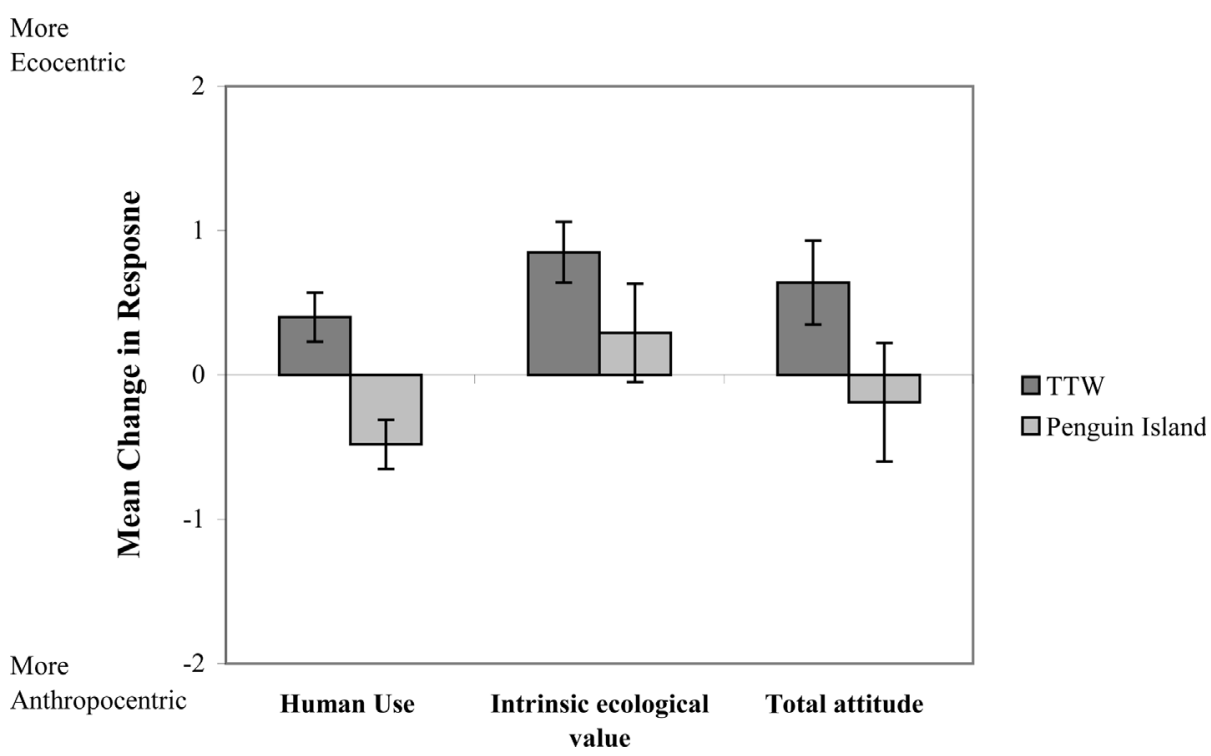

Figure 3 Mean individual change in rating of environmental attitude statements categorised by site. 
change between the TTW site and Penguin Island suggests a diametrically opposite response after experiencing the respective sites despite similar interpretation emphasis on natural area conservation. This is particularly interesting when considering that Penguin Island has a much more intensive investment in on-site interpretation (with an ecological conservation theme) than the TTW site. As the visitor demographics were not significantly different between the sites, we believe that the difference in measured change in environmental attitude is likely to be related to the different experiences afforded by the sites.

The difference in attitude response between the two sites may be related to the site design and available activities. Evison (1981) argued that the character of managed natural areas, and the manner of interaction between people and nature promoted, influenced visitor attitudes to an equal or greater extent than the media installed at a given site. Field and Gough (1998: 39-40) suggested a similar idea when discussing the visitor experience of the tree top fire lookouts in the southwest forests of Western Australia. Display shelters in the area provide interpretation and information relating to the natural and social history of the sites but the actual experience of climbing to the top of the tree gives visitors a 'feel' for the dangers and exertions of the forester's job. Howard (1998) also notes the importance of the actual experience visitors take part in as a significant aspect influencing the success of interpretation and other forms of communication.

Ultimately, the TTW site presents a natural area in the context of a 'look but don't touch' manner, effectively a 'tree museum'. This effect was created by containing visitors within built structures that act as a physical barrier between the people and the natural area attraction. The ecocentric shift toward a stance of 'Intrinsic ecological value' at the TTW site appears to be in contrast to the highly developed character of the site with its overtly engineered infrastructure. However, the significant investment in a built facility located in a geographically isolated forest of rare trees may have heightened the sense that the ecosystem it represents must be of value. Thus the structure seemed to convey perhaps more of a preservation (rather than conservation) message in terms of the intrinsic value of the forest. That is, the Tingle Forest at the TTW site is presented as a valuable ecological specimen preserved for passive appreciation of its intrinsic value rather than its utilitarian worth to humanity.

On the other hand, Penguin Island was designed within a recreational context as a result of a long history of recreational use, pre-dating its status as an ' $\mathrm{A}$ ' class conservation reserve. The ' $\mathrm{A}$ ' class reserve status of the island effectively determines that the conservation of the natural ecosystem is of primary managerial importance. This status is reflected strongly in the ecologically focussed on-site interpretation. Parallel with this, visitors are able to focus on recreational activities by literally immersing themselves in the environment at Penguin Island owing to the primarily aquatic based activities available. Hence the influence on attitudes at this site appeared to manifest as 'conservation through responsible use' of the natural environment-where the island is valued for its service to humans (Hughes \& Morrison-Saunders, 2005). Therefore, while interpretative media may be used to disseminate messages relating to certain themes and concepts, the context of the site experience 
creates the paradigm in which the messages are interpreted or placed. This seems to be the case despite the intensity of interpretation used.

In terms of site design and management, it would seem that the character of the site experience significantly effects the influence of conservation themed interpretation on visitors. The restricted passive observation experience of the TTW was associated with ecocentric shifts in attitude. The diverse and interactive recreational activities at Penguin Island was associated with a greater emphasis on conserving natural areas for their utility to humans.

\section{Perceptions of site experience}

Similarities and differences were found regarding how surveyed visitors perceived their experience of the respective sites. Respondents at both sites rated 'opportunity to experience the beauty of the site' as an important aspect of their experience. Respondents at both sites also rated the statement, 'opportunity to help protect the site' moderately and seemed to increase this rating after their experience. This perhaps relates to the views of Heimstra and McFarling (1974) who hypothesised that people visited natural areas to 'reconnect' with nature and escape from urban living.

There were three aspects rated significantly differently in the responses to each site before the experience that reflected on the particular character of what each site offered. Rating of 'opportunity to recreate at the site' was rated significantly higher by Penguin Island respondents relative to TTW respondents $(z=-5.22, p<0.001)$. Similarly, TTW respondents rated 'opportunity to experience a pristine site' significantly higher than Penguin Island respondents $(z=-2.43, p<0.02)$. This seemed to reflect on the passive observation based experience at TTW, centred on admiration of the forest (a remote tree museum), while Penguin Island offers active recreation in a natural area context (close to urban areas). This perhaps means pristine nature is not as high a priority for Penguin Island respondents.

TTW respondents rated the 'beauty of site' aspect as significantly more applicable than Penguin Island respondents before the experience. This again suggested the aesthetics of the natural surroundings are more important for TTW respondents than those at Penguin Island $(z=-2.28, p<0.05)$. The focus of the TTW site on observation and exploration of the forest contrasted with Penguin Island's more active range of experiences, which in turn affected visitor attitudes toward the site as an experience.

The change in the visitor rating of 'opportunity to learn about site' aspect of the experience was either increased or remained consistently high in the TTW survey result. Penguin Island data indicated a significant decline in rating of this statement after the visit $(z=4.46, p<0.001)$. This result is of interest when considered in the context of the respective intensities of on-site interpretive media used. Penguin Island's relatively high intensity of interpretation seems not to have encouraged perceptions of the site as a learning experience (Figure 4).

It seems that the activity context of the visit, which forms the major difference between the two sites, has influenced visitor perceptions of the learning aspect of the site experience. Some differences of opinion in the literature may be relevant here. McKercher (1993) maintained that natural area visitors were simply 


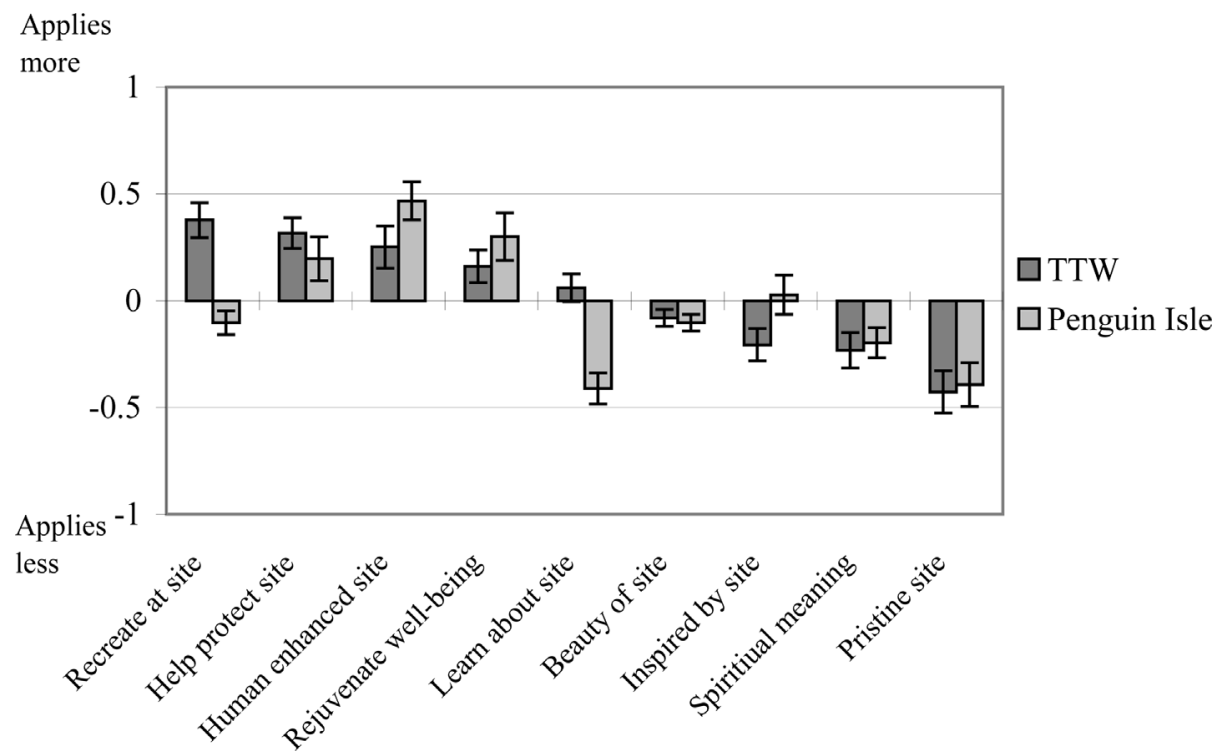

Figure 4 Mean individually calculated change in paired survey ratings of perceptions of TTW and Penguin Island experiences.

leisure consumers and are not seeking intellectual enlightenment. In contrast, Moscardo and Woods $(1998,2001)$ assert that visitors to natural area sites are increasingly expecting educational experiences.

Our study suggests that the context of the site may influence the priority of learning about the natural ecology of the area in question. For example, Moscardo and Woods' (1998) opinion that natural area visitors were increasingly actively seeking knowledge through educational experiences was based on research at the Skyrail in Queensland, Australia. The Skyrail is a high profile, passive observation experience. Visitors travel for several kilometres in a cable car over the canopy of a tropical forest with stops incorporating interpretation centres and boardwalks through the forest. In other words, the Skyrail offers a somewhat similar experience to the TTW except on a much larger scale with more infrastructure and on-site interpretation. The reason for visiting the Skyrail is therefore primarily limited to learning and exploration, as with the TTW. Thus, most of the visitors to Skyrail would probably be interested in accessing interpretation to learn about the forest, which was reflected in the observation of Moscardo and Woods (1998).

This may not be so for other natural area destinations that afford experiences other than those related to learning and exploration. That is, the claim by McKercher (1993) that natural area visitors were simply 'leisure consumers' could be supported by data collected from Penguin Island where a significant number of surveyed people visit the island for reasons other than education owing to the diversity of activities offered. Even when exposed to on-site interpretation, the reason for visiting appeared to override the receptivity to interpretation. Thus, the character of the site may determine whether it is 
visited primarily by 'leisure consumers' or those actively seeking a learning experience.

Respondents at both sites decreased their rating of the 'opportunity to experience a pristine site' statement. This may reflect the small size of each site coupled with the large number of visitors confined to specific areas. Confinement of visitors to small areas coupled with large visitor numbers might often impinge upon enjoyment of the natural aspects of the natural area (Morgan \& Lok, 2000). Thus the higher rating of 'pristine site' before the experience may reflect an underlying urge to get back to nature, as mentioned by Heimstra and McFarling (1974) and Usher et al. (1974). However, the reality of the experience does not afford this opportunity in the eyes of the surveyed visitors.

It seems that the experiential context of the site had a greater influence on respondents than the intensity of interpretation. This was demonstrated by the equal perception of each site as a learning experience before the site encounter followed by a significant reduction in rating of Penguin Island, with its intense on-site interpretation, as a learning experience after the encounter - while this perception of the TTW site remained unchanged.

\section{Diversity of media and influence on visitors}

Media preferences relate to preferred methods of acquiring information, that in turn, may generate a greater efficiency of message and meaning transferral. The TTW site used only one main type of media (text based). This should theoretically restrict its influence on the visitor population as it would exclude those who prefer other forms of interpretation. This appears to have been compensated for in the character and design of the site. All visitors to the site participated in the same activities generally in the same sequence as determined by the one-way TTW walk trail loop followed by the more conventional ground level walk trail loop. Visitors to the TTW site have only a single choice of activity, observation of the forest from two different perspectives. The museum like experience of the TTW therefore may encourage a greater receptivity to the signs. In contrast, the diverse activities available at Penguin Island are complemented by a diverse range of media that supposedly caters for varying preferences amongst the visitor population.

While most visitors surveyed at Penguin Island accessed some form of onsite media, the main focus of the site was as a recreational destination. The TTW is essentially comprised of observational activities within the confines of strictly defined one-way walk trails, placing the focus of the site into a largely learning context. The extent to which on-site interpretive media is used by visitors appears to be intimately linked to the design (hence experiential) focus of the site. Installation of a high intensity of interpretive media in itself does not equate with a higher level of use by, or greater influence on, the visitor population as a whole.

\section{Site design and influence on visitors}

This research demonstrates that the same conservation message presented in different experiential contexts may have entirely different outcomes in terms of 
influence on visitors. That is, the natural area site design is as fundamentally linked to influence on individuals as on-site interpretive media. Authors such as Evison (1981) and McArthur and Hall (1993) have previously highlighted the significant influence of site design on visitor experience. It is thus logical that planning of natural area sites must incorporate any intended educational agenda from the conceptual stages, rather than adding them at a later stage. That is, the type of activity determined by the site design is as much a part of the educational experience as the medium and intensity of interpretation provided.

When this issue is placed in the context of natural area management in Australia, certain complexities become evident. The two sites used in this research have been natural area destinations for many decades prior to the establishment of the department of CALM. Penguin Island and the TTW have a long tradition of visitation that revolves around particular styles of experience specific to each site. The tradition of use arguably did not include conservation as a primary focus. This point is highlighted by the collapse of an iconic tree in the Tingle Forest near the contemporary TTW site that was a direct result of accumulated visitor impacts over a period of 60 years or more (Winfield, 1996). Similarly, Penguin Island was severely ecologically and physically degraded by its long history of recreational use prior to the management regime and infrastructure modifications installed by CALM in the mid-1990s (Dans, 1997; Orr \& Pobar, 1992). Thus, the agency effectively inherited the social history of these natural areas, which did not include a strong conservation ethic, upon which the legislative mandate requires a strong conservation ethic to be applied (CALM, 1996, 2000).

As CALM is a custodian of the public estate, their management approach must theoretically reflect the public interest. This is demonstrated by the management plan that includes Penguin Island emphasising the strong recreational tradition of visitor use of the island (Orr \& Pobar, 1992). The built facilities and management style were thus designed to incorporate this tradition. From this it is apparent that site design may be influenced by visitor demand. If this demand does not include an educational agenda, as suggested by the leisure consumer concept of McKercher (1993), attempts to impose such objectives will be strongly flavoured by the design dictated by the social history of the site.

\section{Conclusions}

It seems that the influence of on-site interpretation on visitors does not rely on investment in a high intensity or variety of on-site interpretation, but is more determined by the context of the site experience and the type of visitors it attracts. The TTW offers a low intensity of primarily text based on-site interpretation coupled with a restriction of activities to a passive observational experience of nature. The TTW site apparently influenced respondents in terms of encouraging a more ecocentric view of the forest. This was perhaps a function of the museum style experience where visitors observe the natural attraction from behind physical barriers, giving the impression of a forest that should not be touched by people, a preserved specimen. 
The diverse range of recreational activities offered by Penguin Island also flavoured the influence of the site experience on respondents. This was evident in the anthropocentric shift in attitudes toward the human use of the environment despite the intensive use of on-site interpretation focused on conservation of the natural area as an important breeding ground for marine fauna. It seems that the conservation message was received in the context of active recreational use of natural areas.

The results of this research point to a tension between catering for the social and recreational history of a site (tradition of use) and contemporary management regimes that seek to introduce conservation agenda requiring encouragement of altered visitor behaviour. These findings were based on primarily quantitative data collection methods, through self administered written surveys using multiple choice questions. Visitor data gathered using quantitative methods has its advantages in terms of comparability of responses, short time required for collection from individuals and potential for larger sample sizes. However, it produces a particular type of data that may not indicate the underlying reasons for responses that may help to explain often complex or contradictory survey results. Future research may gain more detailed insight into the influence of interpretation intensity on the visitor experience, and the relationship between visitor use and management for conservation, through in-depth visitor interviews, visitor group discussions and other more time consuming methods of qualitative data gathering.

The main message for site managers rising from this research concerns the relationship between available site activities and interpretation objectives. Attempts to communicate a strong conservation message may be hampered by the character of activities offered if those activities communicate messages adverse to interpretive themes. For example, the ' $\mathrm{A}$ ' class reserve status of Penguin Island legally identifies it as a high priority conservation zone established primarily for maintenance of ecological integrity. The allowance for continuation of traditional recreational activities, however, communicates a message of conservation for human use. Attempting to thwart almost a century of recreational traditions may be viewed as working against the public interest and generate negative attitudes toward the management regime. It is more difficult to achieve management objectives if visitors do not view them in a positive light. In contrast, the strictly observational activities and infrastructure at the TTW appear to promote the ecological focus of the interpretation. This also seems to compliment the primary reason for visitation (aesthetic appreciation) and so the tradition of use and the conservation agenda opportunistically coincide.

To ensure complementary messages, on-site interpretive media design should be incorporated into the total site design at the planning stage rather than as a post hoc add-on as is commonly practiced. This will ensure that the presentation of the on-site interpretation will meld with the site design and activities through careful consideration of what is most appropriate for a specific site. In addition, the tension between catering for a tradition of use and applying conservation focussed management regimes may require onsite communication to be carefully crafted to ensure a positive relationship with visitors. This may be especially important where a newly determined 
conservation status requires changes in visitor perceptions and attitudes toward the site. This would ideally require employment of staff with psychology backgrounds who could design on-site communication based application of psychological theory and on-going monitoring of visitor attitudes, perceptions and behaviour. Creating such capacity within protected area management may increase the ability for understanding visitor attitudes and perceptions and integrating them into the planning and design processes for a specific site. This would ideally create a greater consistency between what the physical site design communicates and the intended messages of onsite interpretive media.

\section{Correspondence}

Any correspondence should be directed to Michael Hughes, Curtin Sustainable Tourism Centre, Curtin University of Technology, GPO Box U1987, Perth, WA 6485, Australia (michael.hughes@cbs.curtin.edu.au).

\section{References}

ANZECC (1999) Best Practice in Park Interpretation and Education. Department of Natural Resources and Environment: Victoria, Australia.

Austats (2003) Census of Population and Housing: Local Government Areas. On WWW at: http://www.abs.gov.au/ausstats [accessed July 19, 2003].

Ballantyne, R. (1998) Interpreting 'visions': Addressing environmental education goals through interpretation. In Contemporary Issues in D. Uzzell and R. Ballantyne (eds) Heritage \& Environmental Interpretation. London: The Stationery Office.

Ballantyne, R., Packer, J. and Beckman, E. (1998) Targeted interpretation: Exploring relationships among visitors' motivations, activities, attitudes, information needs and preferences. Journal of Tourism Studies 9 (2), 14-25.

Bramwell, B. and Lane, B. (1993) Interpretation and sustainable tourism: The potential and the pitfalls. Journal of Sustainable Tourism 1 (2), 71-80.

CALM (1996) Recreation and Tourism Strategy 1996-2000. Department of Conservation and Land Management: Kensington, Western Australia.

CALM (1996) Sea Lions and Fur Seals. Department of Conservation and Land Management: Kensington, Western Australia.

CALM (2000) CALM Corporate Plan 2000-2005. Department of Conservation and Land Management: Kensington, Western Australia.

Dans, P. (1997) The changing face of Penguin Island. Landscope (Summer), 28-35.

Dunlap, R.E. and Liere, K.D.V. (1978) The new environmental paradigm. Journal of Environmental Education 9 (4), 10-19.

Evison, B. (1981) Park 'image' as its own best defence. Journal of Environmental Education $12(4), 14-15$.

Fakeye, P.C. and Crompton, J.L. (1992) Importance of socialisation to repeat visitation. Annals of Tourism Research 19 (3), 364-367.

Field, G. and Gough, D. (1998) The art of interpretation. Landscope (Winter), 36-41.

Heimstra, N. and McFarling, L. (1974) The natural environment and behaviour. In G. Holloway (ed.) Environmental Psychology. Belmont: Wadsworth Publishing Co. Inc.

Howard, J. (1998) Environmental education and interpretation: Developing an affective difference. Australian Journal of Environmental Education 14, 65-69.

Hughes, M. and Morrison-Saunders, A. (2002) Repeat and first time visitation in an experience specific context, the Valley of the Giants Tree Top Walk. Journal of Tourism Studies 13 (1), 20-25.

Hughes, M. and Morrison-Saunders, A. (2003) Visitor attitudes toward a modified natural attraction. Society $\mathcal{E}$ Natural Resources 16 (3), 191-203. 
Hughes, M. and Morrison-Saunders, A. (2005) Interpretation, activity participation and environmental attitudes of visitors to Penguin Island, Western Australia. Society $\mathcal{E}$ Natural Resources 18 (7), 611-624.

Jurowski, C., Uysal, M., Williams, D. and Poe, F. (1995) An examination of preferences and evaluations of visitors based on environmental attitudes: Biscayne Bay National Park. Journal of Sustainable Tourism 3 (2), 73-86.

Manning, R., Valliere, W. and Minteer, B. (1999) Values, ethics and attitudes toward national forest management: An empirical study. Society \& Natural Resources 12 (5), 421-436.

McArthur, S. (1994) Evaluating interpretation: What's been done and where to from here? Paper read at Third Annual Conference of the Interpretation Australia Association Inc. Collingwood, Australia.

McArthur, S. and Hall, C.M. (1993) Visitor management and interpretation at heritage sites. In M. Hall and S. McArthur (eds) Heritage Management in New Zealand and Australia: Visitor Management, Interpretation and Marketing. Auckland: Oxford University Press.

McKercher, B. (1993) Some fundamental truths about tourism: Understanding tourism's social and environmental impacts. Journal of Sustainable Tourism 1 (1), 6-15.

Morgan, D. and Lok, L. (2000) Assessment of a comfort indicator for natural tourist attractions: The case of visitors to Hanging Rock, Victoria. Journal of Sustainable Tourism 8 (5), 393-409.

Moscardo, G. and Woods, B. (1998) Educating Visitors: What are the Benefits for Tourism? CRC for Tropical Research Ecology: Cairns, Australia.

Moscardo, G. and Woods, B. (2001) The future of interpretive signs. Paper read at The World Congress Heritage Interpretation International. Collingwood, Australia

Neuman, W.L. (2000) Social Research Methods: Qualitative and Quantitative Approaches (3rd edn). Boston: Allyn and Bacon.

Orr, K. and Pobar, G. (1992) Shoalwater Islands Management Plan 1992-2002. Department of Conservation and Land Management: Kensington, Western Australia.

Roggenbuck, J. (1992) Use of persuasion to reduce resource impacts and visitor conflicts. In M. Manfredo (ed.) Influencing Human Behaviour. Champaign, IL: Sagamore Publishing Company.

Rolston, H. (1998) Aesthetic experience in forests. The Journal of Aesthetics and Art Criticism 56 (2), 157-166.

Usher, M., Pitt, M. and Boer, G.D. (1974) Recreational pressure in the summer months on a nature reserve on the Yorkshire coast, England. Environmental Conservation 1 (1), $43-49$.

Uzzell, D. (1998) Planning for interpretive experiences. In D. Uzzell and R. Ballantyne (eds) Contemporary Issues in Heritage \& Environmental Interpretation. London: The Stationery Office.

Winfield, R. (1996) Saving the giants. Landscope (Winter), 10-16. 